\title{
Sensitivity Improvement of Thermoelectric Hydrocarbon Sensors: Combination of Glass-Ceramic Tapes and Alumina Substrates ${ }^{\dagger}$
}

\author{
Jaroslaw Kita *, Gunter Hagen, Christopher Schmitt and Ralf Moos \\ Department of Functional Materials, University of Bayreuth, D-95440 Bayreuth, Germany; \\ Functional.Materials@uni-bayreuth.de (G.H.); Functional.Materials@uni-bayreuth.de (C.S.); \\ Functional.Materials@uni-bayreuth.de (R.M.) \\ * Correspondence: Functional.Materials@uni-bayreuth.de; Tel.: +49-921-557-407 \\ + Presented at the Eurosensors 2017 Conference, Paris, France, 3-6 September 2017.
}

Published: date

\begin{abstract}
This contribution presents the integration of glass-ceramic tapes on alumina substrates to increase the sensitivity of thermoelectric hydrocarbon gas sensors. Both ceramic materials have different thermal conductivity. Their combination into one sensor structure significantly improves the sensitivity by at the same time maintaining the excellent mechanical stability at high temperatures. Furthermore, this special technology allows for an easy integration of additional functional elements such as screen-printed thermocouples for temperature control purposes.
\end{abstract}

Keywords: HC sensor; thermoelectric hydrocarbon sensors; thick-film; alumina; LTCC; exhaust monitoring

\section{Introduction}

Many applications require high-temperature stable and highly sensitive hydrocarbon (HC) sensors, especially for automotive exhaust applications [1-4]. In previous works, a sensor based on the thermoelectric principle was successfully tested for application in automotive exhausts [4,5]. Such sensors are built as follows: On the front side of a ceramic substrate, two conducting materials (here: gold and platinum) are screen-printed to form a stack of thermocouples (thermopile). The area of one junction is covered with an inert layer whereas the other one is coated with a catalyst (Figure 1).

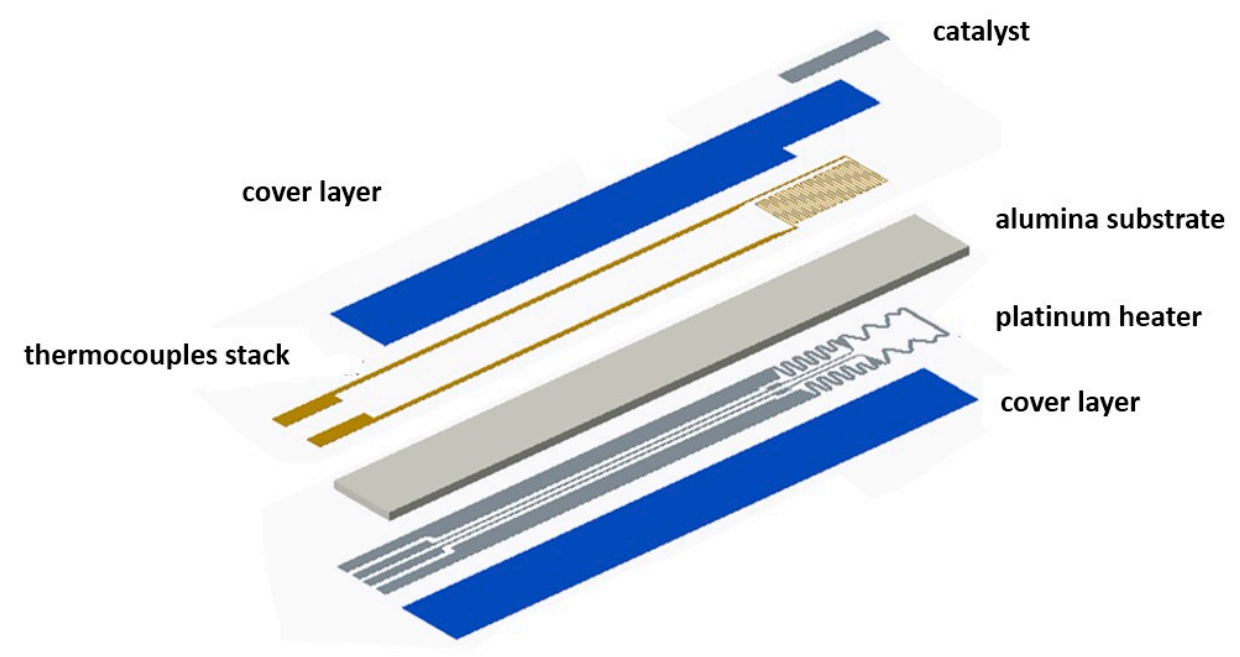

Figure 1. Scheme of the thermoelectric hydrocarbon sensor. 
An integrated thick-film heater on the reverse side sets the absolute sensor temperature (e.g., to $600{ }^{\circ} \mathrm{C}$ ) to keep the catalyst active. Exothermic oxidation of hydrocarbons leads to a temperature increase at the active coating, which generates a thermo-voltage between both junctions. This sensor response depends linearly on the HC concentration, shows a long-term stable signal, and fast response and recovery times.

Its sensitivity depends also on the substrate material, respectively its thermal conductivity $\lambda$, due to the heat transfer between both junctions. Whereas alumina-based sensors offer good mechanical stability at high temperatures, their sensitivity is low due to its relatively high thermal conductivity. Using LTCC ceramics as substrate material with low thermal conductivity increases sensitivity, but the homogeneity of the temperature field becomes worse [6]. Moreover, LTCC-based sensors are less long-term stable at high temperatures. This effect has already been very successfully applied to build an LTCC-based differential scanning calorimeter (DSC) $[7,8]$.

In this study, we show how such thermoelectric devices can be improved significantly with respect to sensitivity by maintaining both a large homogenous temperature field in the desired area and the mechanical stability. To achieve this, both above mentioned substrate materials and techniques were combined.

\section{Sensor Construction}

The design of the sensor was supported by FEM analysis. The main goal of the FEM analysis was to find an optimal LTCC layer thickness at which the sensor signal becomes as high as possible (temperature difference $\Delta T$ horizontal between catalytically active layer and inert layer). At the same time, the vertical temperature difference $\Delta T_{\text {vertical }}$ between front and reverse side of the heater area should be as small as possible. The simulation results are summarized in Figure 2.

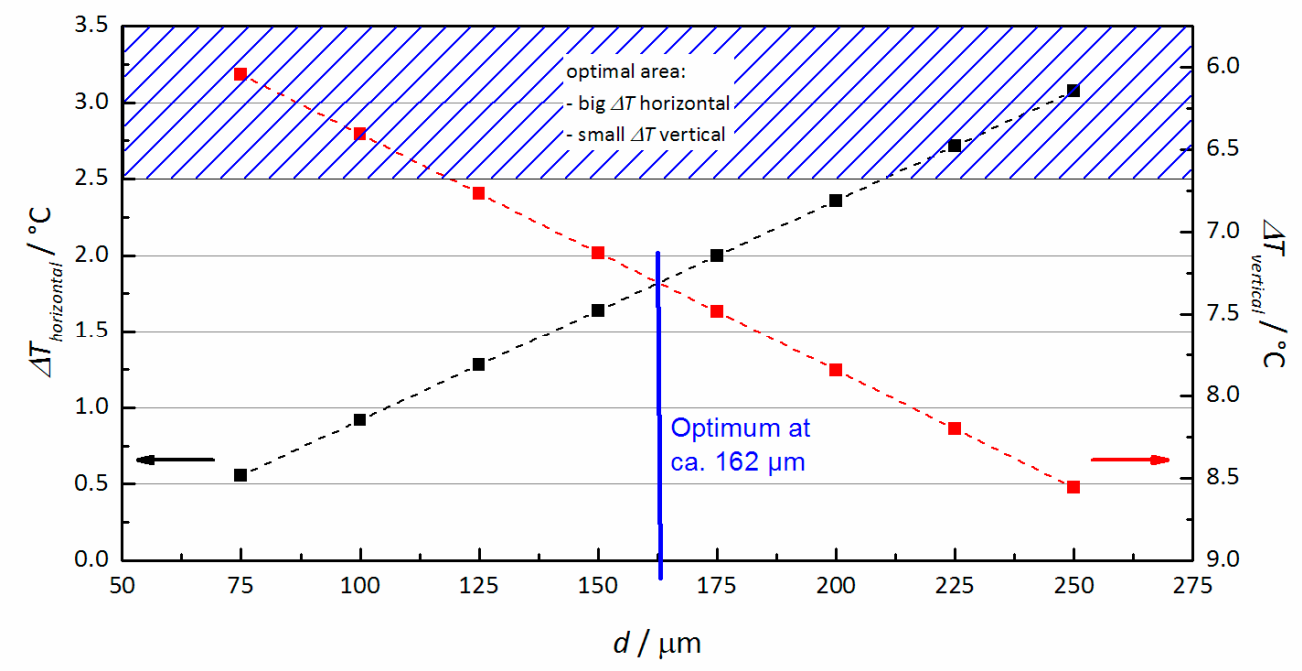

Figure 2. New thermoelectric sensor with a low temperature transfer tape (LTTT) layer laminated on alumina substrate.

As expected, the sensor signal increases when the LTCC layer thickness $d$ is increased. However, the vertical temperature difference increases as well. An optimum LTCC layer thickness is about 160 $\mu \mathrm{m}$. Since the thicknesses of commercially available tapes are standardized, we decided to build two versions of sensors, with LTCC layer thicknesses of about $110 \mu \mathrm{m}$ and $230 \mu \mathrm{m}$, respectively.

As basic substrates, a 96\% alumina (Ceramtec) with already screen-printed and fired platinum heaters on the reverse side and a single thick-film type-S thermocouple (Pt/PtRh, DuPont, for details see [9]) for temperature control on the front side were used. Then, a low temperature transfer tape (LTTT, ESL 41020) was laminated and co-fired at $850^{\circ} \mathrm{C}$ onto the front side.

As mentioned above, we manufactured two different types of sensors to measure the influence of LTTT layer thickness on the sensor sensitivity: $110 \mu \mathrm{m}$ and $230 \mu \mathrm{m}$. Upon the LTTT, the thermopile 
structure $(\mathrm{Au} / \mathrm{Pt}, 15$ thermocouples in series) as well as the catalyst (alumina with $1 \mathrm{wt} \% \mathrm{Pt}$ ) were screen-printed and fired (Figure 3).

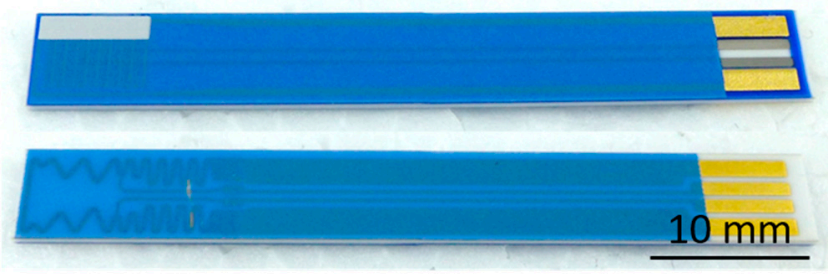

Figure 3. New thermoelectric sensor with LTTT layer laminated on alumina substrate.

\section{Sensor Characterization}

These sensor devices were characterized in a lab test bench by admixing different propene concentrations to a base gas $\left(\mathrm{N}_{2} / 10 \% \mathrm{O}_{2}\right)$. Time dependent data were evaluated to characteristic curves (Figure 4).

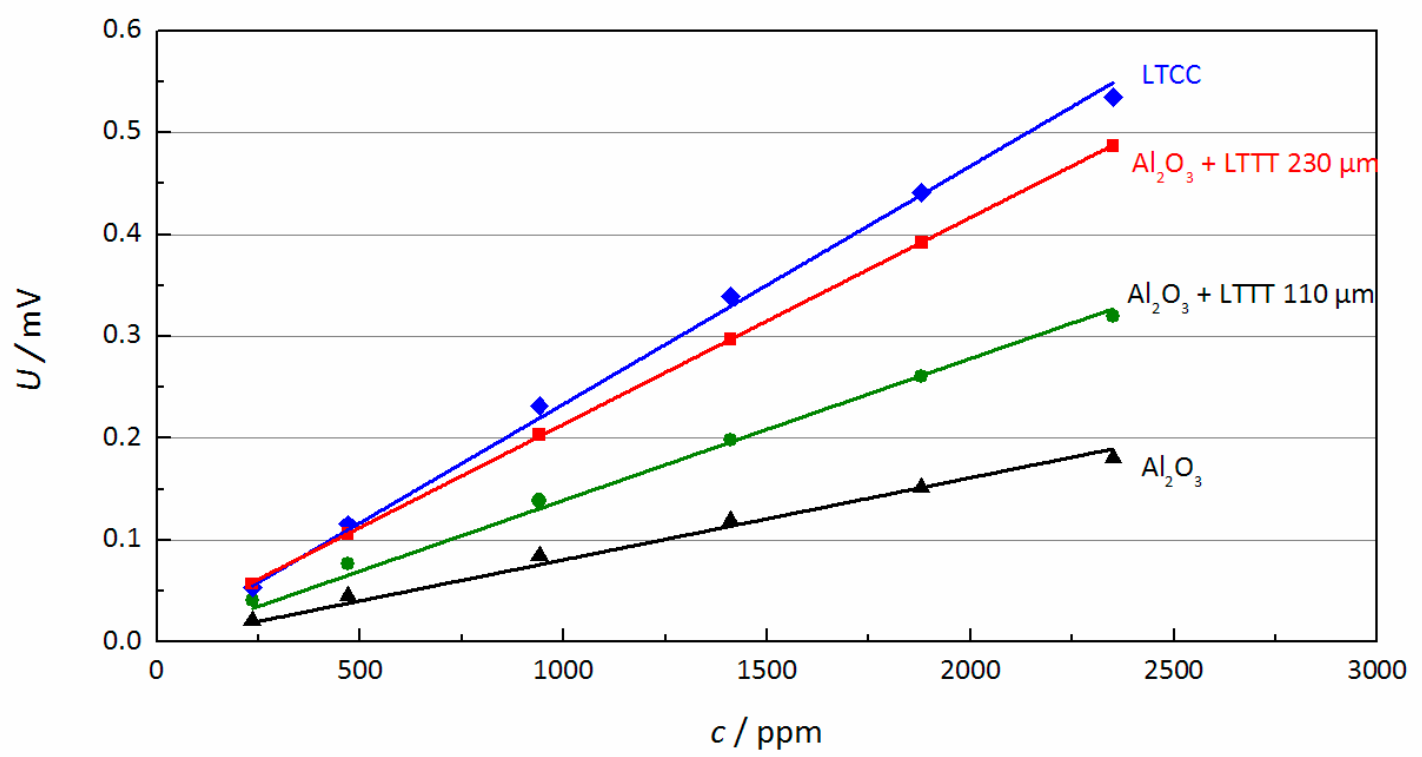

Figure 4. Comparison of sensor sensitivity to propane for different substrates/materials combination.

All sensors showed a linear dependency on the HC concentration, but one can clearly see the influence of the substrate material. The sensitivity for sensors on pure LTCC substrates $(\lambda=2.8$ $\mathrm{W} / \mathrm{mK})$ is three times higher than for sensors made of alumina substrates $\left(\lambda \sim 9 \mathrm{~W} / \mathrm{mK} @ 600{ }^{\circ} \mathrm{C},[10]\right.$. The introduction of LTTT layers improve significantly the sensors sensitivity compared to the alumina-based devices. For a $110 \mu \mathrm{m}$ thick LTTT layer, the sensor signal is as twice as high. A 230$\mu \mathrm{m}$ layer shows characteristics close to LTCC-based sensors.

\section{Conclusions}

In this study it was shown that the combination of two materials with different thermal properties can significantly improve the sensor sensitivity, maintaining at the same time the necessary mechanical and long-term stability. The presented hydrocarbon sensors can be used not only to monitor automotive exhausts, but can also find applications, for instance, in gas analysis of firewood combustion processes [11].

To enhance the selectivity, a temperature-modulated operation (in the range of 100 to $600{ }^{\circ} \mathrm{C}$ ) was suggested in [12]. Depending on the catalyst material, different gas species start to react at certain temperatures. So, one can distinguish between various hydrocarbons by measuring their light-off 
behavior. The here-presented setup is beneficial for such applications due to the possibility to integrate an additional thermocouple for more precise temperature control.

Author Contributions: G.H. designed experiments, while C.S. performed experiments. C.S. and G.H. analyzed the data and evaluated the results. G.H., J.K. and R.M. supervised the work, J.K., G.H. and R.M. wrote the paper.

Conflicts of Interest: The authors declare no conflict of interest. The founding sponsors had no role in the design of the study; in the collection, analyses, or interpretation of data; in the writing of the manuscript, and in the decision to publish the results.

\section{References}

1. Riegel, J.; Neumann, H.; Wiedemann, H.-M. Exhaust gas sensors for automotive emission control. Solid State Ion. 2002, 152-153, 783-800, doi:10.1016/S0167-2738(02)00329-6.

2. Moos, R. A brief overview on automotive exhaust gas sensors based on electroceramics. Int. J. Appl. Ceram. Technol. 2005, 2, 401-413, doi:10.1111/j.1744-7402.2005.02041.x.

3. Sahner, K.; Fleischer, M.; Magori, E.; Meixner, H.; Deerberg, J.; Moos, R. HC-sensor for exhaust gases based on semiconducting doped $\mathrm{SrTiO}_{3}$ for On-Board Diagnosis. Sens. Actuators B Chem. 2006, 114, 861-868, doi:10.1016/j.snb.2005.08.005.

4. Wu, M.; Micheli, A. Calorimetric hydrocarbon sensor for automotive exhaust applications. Sens. Actuators B Chem. 2004, 100, 291-297, doi:10.1016/j.snb.2003.11.010.

5. Wiegärtner, S.; Hagen, G.; Kita, J.; Reitmeier, W.; Hien, M.; Grass, P.; Moos, R. Thermoelectric hydrocarbon sensor in thick-film technology for on-board-diagnostics of a diesel oxidation catalyst. Sens. Actuators $B$ Chem. 2015, 214, 234-240, doi:10.1016/j.snb.2015.02.083.

6. Kita, J.; Rettig, F.; Moos, R.; Drüe, K.-H.; Thust, H. Hot-Plate Gas Sensors-Are Ceramics Better? Int. J. Appl. Ceram. Technol. 2005, 2, 383-389, doi:10.1111/j.1744-7402.2005.02037.x.

7. Kita, J.; Missal, W.; Wappler, E.; Bechtold, F.; Moos, R. Development of a miniaturized ceramic differential calorimeter device in LTCC technology. J. Ceram. Sci. Technol. 2014, 4, 137-144, doi:10.4416/JCST2013-00008.

8. Missal, W.; Kita, J.; Wappler, E.; Gora, F.; Kipka, A.; Bartnitzek, T.; Bechtold, F.; Schabbel, D.; Pawlowski, B.; Moos, R. Miniaturized ceramic differential scanning calorimeter with integrated oven and crucible in LTCC technology. Sens. Actuators A Phys. 2011, 172, 21-26, doi:10.1016/j.sna.2011.01.025.

9. Kita, J.; Wiegärtner, S.; Moos, R.; Weigand, P.; Pliscott, A.; LaBranche, M.H.; Glicksman, H.D. Screenprintable type $S$ thermocouple for thick-film technology. Procedia Eng. 2015, 120, 828-831, doi:10.1016/j.proeng.2015.08.

10. Kita, J.; Engelbrecht, A.; Schubert, F.; Groß, A.; Rettig, F.; Moos, R. Some practical points to consider with respect to thermal conductivity and electrical resistivity of ceramic substrates for high-temperature gas sensors. Sens. Actuators B Chem. 2015, 213, 541-546, doi:10.1016/j.snb.2015.01.041.

11. Ojha, B.; Illyaskutty, N.; Knoblauch, J.; Balachandran, M.R.; Kohler, H. High-temperature CO/HC gas sensors to optimize firewood combustion in low-power fireplaces. J. Sens. Sens. Syst. 2017, 6, 237-246, doi:10.5194/jsss-6-237-2017.

12. Hagen, G.; Leupold, N.; Wiegärtner, S.; Moos, R. Sensor Tool for Fast Catalyst Material Characterization. Top. Catal. 2017, 60, 312-317, doi:10.1007/s11244-016-0617-8.

(C) 2017 by the authors. Licensee MDPI, Basel, Switzerland. This article is an open access article distributed under the terms and conditions of the Creative Commons Attribution (CC BY) license (http://creativecommons.org/licenses/by/4.0/) 